\title{
OBITUÁRIO DE SONIA MACHADO DE CAMPOS DIETRICH
}

\section{7/01/1935 -10/08/2012}

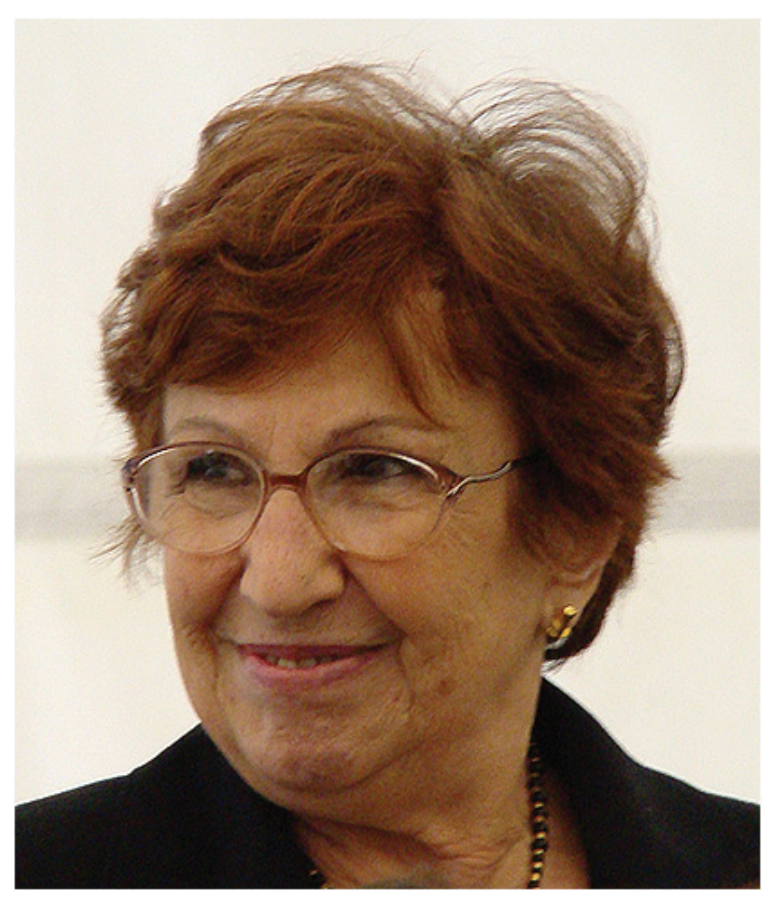

E assim, enquanto dormia e com a certeza do dever cumprido, ela fez sua passagem de forma serena para se juntar a outros grandes cientistas brasileiros, como Labouriau e Gottlieb, que tanto admirava. Sonia era Machado de Campos de nascimento e Dietrich após o casamento. Teve 4 filhos, Flávia, Paula, Cláudia (in memoriam) e Peter, que lhe deram 6 netos. Dotada de inteligência incomum e personalidade marcante, trocou na infância, como ela dizia, o balé pela esgrima. Sonia graduou-se em História Natural pela Universidade de São Paulo (USP) em 1957, tendo realizado especializações em Fisiologia Vegetal na USP e no Instituto de Botânica entre 1957 e 1961. Em 1960, ao acompanhar seu marido Peter Dietrich, teve a oportunidade de trabalhar na Universidad de Buenos Aires-Argentina, especializando-se em Química Biológica, particularmente no metabolismo de carboidratos, no Instituto Fundação Campomar, dirigido por Luis Federico Leloir (Prêmio Nobel de Química em 1970). De 1964-1966 trabalhou com Bioquímica na University of Wisonsin - Madison, EUA e de 1967-1969 fez seu PhD também em Bioquímica, trabalhando na University of Saskatchewan, Canadá, com biossíntese de alcalóides. Sua inteligência e vivacidade, aliadas às oportunidades de trabalhar no exterior, resultaram em mais uma de suas grandes habilidades, a de escrever e falar fluentemente Espanhol e Inglês. Sonia trabalhou como pesquisadora científica no Instituto de Botânica de 1959 a 1992, quando se aposentou, mas permaneceu na Instituição como pesquisadora visitante até o seu último dia de vida, sendo Bolsista de Produtividade Científica do CNPq, na Categoria Sênior, a partir de 2007. Enérgica e incansável, ela imprimia rigor e qualidade a tudo que fazia. Ela foi professora credenciada nos cursos de pósgraduação em Biologia Molecular da Escola Paulista de Medicina (hoje UNIFESP), em Biologia Vegetal da UNICAMP e em Botânica da USP, tendo orientado 12 Mestres e 15 doutores. Publicou 102 artigos científicos e 7 capítulos de livro, tendo se destacado nos estudos com paredes celulares de fungos e plantas, carboidratos de reserva de órgãos subterrâneos e de sementes e respostas de defesa em plantas. Recebeu vários prêmios e títulos, como o Prêmio Schering concedido pela Sociedade Brasileira de Microbiologia por duas vezes, em 1978 e 1983 e ABiFARMA Associação Brasileira das Indústrias Farmacêuticas (1979). Em 1998 foi condecorada como Comendadora da ordem do Mérito Científico, da Presidência da República. Sonia foi Chefe da Seção de Fitoecologia, 
Diretora Geral do Instituto de Botânica, Criadora e Coordenadora Geral do Curso de Pós-Graduação em Biodiversidade Vegetal e Meio Ambiente do Instituto de Botânica, sendo Pró-Reitora desta Instituição de Ensino por dois triênios e Presidente da Comissão Permanente em Regime de Tempo Integral. Sua competência científica, seu entusiasmo e espírito de liderança a tornaram reconhecida mundialmente, tendo participado de diversas comissões e conselhos nacionais e internacionais como membro do Comitê Nacional do Brasil da Rede Latinoamericana de Ciências Biológicas, assessora da International Foundation of Science, da Academia de Ciências para o Mundo em Desenvolvimento (Third World Academy of Science (TWAS), da National Geographic Society e da Rede Latinoamericana de Botânica, da qual foi fundadora e coordenadora, membro do CONABIO, do Ministério do Meio Ambiente e da Amazônia Legal. Foi também membro da Academia Brasileira de Ciências, Vice-Presidente do Conselho Federal de Biologia e Editora das Revistas Hoehnea, Brazilian Journal of Botany e Membro do Corpo Editorial da Ciência e Cultura e do Brazilian Journal of Biology. Em uma época em que a internacionalização da ciência não era prioridade, Sonia com sua enorme visão de futuro, já reconhecia a importância das colaborações externas para a realização de pesquisas de vanguarda. Foi assim que estimulou muitos colegas e estudantes a realizarem estágios no exterior, em centros de excelência da Europa e Estados Unidos, empenhando-se em projetar a Botânica brasileira no cenário mundial. A partir de 2010, temendo a extinção da Sociedade Botânica de São Paulo, assumiu a Presidência da SBSP e a Editoria Chefe da Revista Brasileira de Botânica e graças ao seu trabalho competente e incansável revitalizou a Sociedade e a Revista e logrou, em 2012, editar o primeiro fascículo da RBB totalmente em inglês. Horas antes de nos deixar, comemorava feliz a assinatura do contrato da RBB com a editora Springer. Quem teve a oportunidade de conviver mais de perto com ela, sabia que Sonia era uma mulher admirável, de personalidade forte e dotada de uma sagacidade incomum. Ela era alegre, divertida, passional, companheira, amiga carinhosa, mãe zelosa e avó dedicada. Sonia deixou um enorme legado que jamais será esquecido e muitos exemplos a serem seguidos. Sem dúvida, ela fará uma falta enorme à ciência brasileira, da América Latina e do mundo e mais ainda a todos que ao longo de suas vidas tiveram o privilégio de conhecê-la e conviver com ela por décadas.

Márcia R. Braga e

Rita de Cássia L. Figueiredo Ribeiro

Pesquisadoras Científicas VI do Instituto de Botânica 